\title{
Who counts as a parent for the purposes of filial obligations?
}

\section{Cameron Fenton}

\author{
Department of Philosophy, Western University, cfenton@gmail.com
}

DOI: http://dx.doi.org/10.5324/eip.v11i1.2245

This is an open access article distributed under the terms of the Creative Commons
Attribution 4.0 International License, which permits unrestricted use, distribution, and
reproduction in any medium, provided the original author and source are credited.

I argue that using a traditional biological account of parenthood causes problems for determining who counts as a parent for the purposes of filial obligations in alternative family structures. I then argue that a better way to understand parenthood is as a role. People who fill the role of parents are parents, regardless of their biological ties to a child. Next, I argue that children can have more than two parents and so can have filial obligations to more than two people. I then demonstrate that understanding parenthood as a role allows us to correctly account for who should be a parent in cases of adoption, surrogacy, and extended families. In the final section I discuss three related worries about allowing a child to have more than two parents.

Keywords: Filial obligations, parent-child relationships, family ethics, alternative families, parenthood

\section{Introduction}

Filial obligations are special obligations that we have to our parents. Theories of filial obligations, such as the friendship, gratitude, and special goods theories, try to tell us what obligations we have to our parents and why we have them. However, little attention has been paid to who counts as a parent for the purposes of filial obligations. I suspect this is because the literature on filial obligations in contemporary Western philosophy is minimal. Most authors implicitly assume that every child has two parents, usually one male and one female, and usually biologically related to the child. ${ }^{1}$ I'll call this structure the traditional account of the family. Though it's true that many children grow up in traditional families, alternative family structures need consideration and have so far been ignored in the literature on filial obligations. ${ }^{2}$

I have two goals. First, I want to show that a strict traditional account of the family can create a problem for existing theories of filial obligations. I demonstrate this by arguing that the special goods theory of filial obligations has trouble differentiating between parents and very close family members, if we use the traditional account of the family.

Second, I argue that for the purposes of filial obligations, being a parent is determined by the role one plays in the care and upbringing of a child, and not solely by a biological relationship. I then discuss three different kinds of alternative 
family structures-adoption, surrogacy, and extended family-and demonstrate that a child can have parents who are very different from those in the traditional structure. This means that children can have filial obligations to more, or fewer, than two people. If we are limited to the traditional account of the family, theories of filial obligations will have difficulty accounting for filial obligations in these alternative family structures.

I won't discuss the content of filial obligations here, nor will I argue for their existence. While these are interesting topics, I think we can determine who counts as a parent for the purposes of filial obligations without a definitive account of the content of filial obligations. I will assume that we have some filial obligations, and that these obligations require us to help our parents when they are in need.

Once we know what makes someone a parent, we can then apply a theory of filial obligations to that person to determine if their children have obligations. For example, being a parent does not preclude being a bad parent, so you might count as a parent for the purposes of filial obligations, but still be owed nothing because you failed to discharge your parental duties.

It is also important to point out that I am interested in parenthood as a moral concept. I expect that most of the people I claim are parents would not be recognized as legal parents. The law has been slow to adapt to the social changes that have led to children having more than two potential parents. The law is also very binary when determining who is a parent, that is, either one is a legal parent, or one is effectively a stranger (Young 1997-1998: 520). Fortunately, filial obligations are, for the most part, moral obligations. ${ }^{3}$ This means that people can be parents for the purposes of filial obligations, without necessarily being legal parents.

\section{Setting up the problem}

To set up the problem I see with the traditional account of parenthood, I explain how a restrictive understanding of parenthood can lead to problems for theories of filial obligations. I use Simon Keller's special goods theory of filial obligations as an example (Keller, 2006). I focus on Keller's theory for two reasons: first, discussing every theory of filial obligations would require a much longer paper, and second, using the traditional account of parenthood creates a clear problem for Keller's theory. That said, using only the traditional account of parenthood would be problematic for the friendship and gratitude theories as well, if only because they too would then be unable to account for alternative family structures.

To be clear, I am arguing that using the traditional account of the family can be problematic for theories of filial obligations. I am also suggesting that the traditional account of the family is often used as the assumed default model of the family. I do not argue that existing theories of filial obligations require the use of the traditional account of the family. I think the friendship, gratitude, and special goods theories of filial obligations are all compatible with alternative accounts of the family. However, existing work in the literature does not explore how filial obligations work in alternative family structures, apart from a few authors who consider adoption. ${ }^{5} \mathrm{I}$ argue that there is another way to think about parenthood that can better explain filial obligations in alternative family structures, regardless of which theory of filial obligations we might use. As already mentioned, I think we can determine who counts as a parent for the purposes of filial obligations before we decide which 
theory of filial obligations provides the best account of the content of filial obligations.

\section{Keller's Special Goods Theory}

Keller claims that we owe our parents the special goods that can be produced from the reciprocal relationship we share. Special goods are those goods that can only be obtained within a parent-child relationship. Keller's primary example of a special good is a child keeping in touch with his or her parents (Keller 2006: 266). It is not that the child's parents want to be in touch with someone and the child just happens to fill that role, rather the parents want to be in touch with their child and no one else can fill that role.

Keller contrasts special goods with generic goods, which are those goods that can, in principle, be obtained from anyone. For example, getting a drive to the grocery store is a generic good because it can be accomplished by hiring a taxi. We owe our parents special goods because we are uniquely placed to provide these goods (Keller 2006: 268).

The special goods theory requires us to provide our parents with the special goods they need and we are able to provide. We have obligations to our parents because of the reciprocal relationship we share. Keller claims that the parent-child relationship is different in kind from other close relationships and is able to produce goods that are not available elsewhere.

One concern for the special goods theory is that special goods may not be as special as Keller claims. If other people can provide the same goods as one's children, then filial relationships do not create any special goods. This challenge can be presented at least two ways. First, one might think that what Keller identifies as special goods are really just generic goods. In this case, anyone - at least in principle - could supply the goods. I do not find this view very plausible, and I think Keller's main example of a special good demonstrates this. If no special goods exist, then having anyone keep in touch would be just as valuable to parents as having their children keep in touch. This seems false in all but the worst parent-child relationships. The good created by the knowledge that your child cares about your welfare and happiness surely adds something to the good of keeping in touch with someone.

The second way to frame this challenge is to grant that certain goods are achievable only in the right kind of relationship, but acknowledge that someone else could fill the role Keller reserves for children and parents. For example, one might believe a niece or nephew could provide the same goods as a child, provided the relationship was similar to a parent-child relationship. Similarly, perhaps a grandparent-grandchild relationship could produce many of the same goods as a parent-child relationship. If it is true that other relationships can produce the same goods as parent-child relationships, then the special goods theory needs to be able to account for these relationships. Otherwise, there is little reason to think that special goods are all that special.

This is where I believe it becomes very important to define who counts as a parent. This challenge to the special goods theory only has force if we think grandparents, aunts, and uncles cannot be parents. If they can be parents, then it is not a problem to say that special goods can come from their relationship with a 
child. The goods produced are still special because these people fill the role of parents, even if they are not biological parents.

\section{Parenting as a role}

Theories of parenthood include genetic, labor-based, intentional, and causal accounts (Brake \& Millum, 2016). These theories seek to determine who has the rights and responsibilities for a particular child. They are, for the most part, forward-looking. That is, they are interested in who should bear the rights and responsibilities for a child, while the child is still young. ${ }^{6}$ Investigating the obligations of adult children allows one to be backward-looking. I am interested in who actually possessed the rights and responsibilities for a child and whether they did a good job managing those rights and responsibilities. I am not interested in whether a person who played no role in the child's life could have been a better parent than the one the child had. This backward-looking perspective allows me to stipulate the conditions for parenthood and then examine the people involved in a child's upbringing to see if they meet those conditions.

Put simply, for the purposes of filial obligations, I think whoever takes care of a child's needs, has nurtured and cared for him or her, and showed a long-term interest in his or her development into adulthood can be defined as a child's parents. ${ }^{7}$ The most immediate consequence of this definition of parenthood is that it does not matter who the child's biological parents are. Biological parents can be parents for the purposes of filial obligations, but only if they are also the people who took care of their child's needs, nurtured and cared for him or her, and showed a long-term interest in his or her development into adulthood. If someone else does these things for the child, then that person is the child's parent. A biological relationship does not automatically make someone a parent.

An example will help to demonstrate why a biological connection alone is not sufficient to make a parent. Imagine that a man who abandoned his child shortly after birth later claims he is owed filial obligations. Despite not playing a role in the child's upbringing, he feels his biological connection to his child is sufficient to support filial obligations. Suppose also that the child was raised by his mother and her new husband. If we base parenthood solely on genetics, then the biological father is the child's parent, while the mother's new husband is not. Using my theory of parenthood, the mother's new husband is a parent, while the biological father is not. I think my theory of parenthood produces a far more intuitive result. The child knows and loves his mother's new husband and does not know or love his biological father. Furthermore, his mother's new husband took care of his needs, nurtured and cared for him, and showed a long-term interest in his development, while his biological father did none of these things. Viewing the child's biological father as a parent, and not the mother's new husband, would require us to think that genetics are more important for determining parenthood than the love, time and resources of the person who raised the child and whom the child knows and loves. This seems to me to be a clear mistake.

In the literature on parenthood, the conception of parenthood as a role is commonly held. ${ }^{8}$ For example, Elizabeth Brake argues that parenthood is a social role that people come to occupy through voluntary acceptance (Brake, 2010). In the most straightforward cases, couples consciously decide they want to procreate and 
take on the role of parents. However, Brake argues that people can also tacitly accept the role of parents. She says, "Thus, when someone has chosen not to abort, undergone pre-natal medical care, bought some baby clothes, and taken an infant home, the role of parent has been tacitly accepted (Brake 2010: 171)." Once someone has voluntarily accepted the role of a parent, he or she takes on the obligations that go along with that role. The content of parental obligations will vary according to the social and legal expectations of the society in which the parents live (Brake 2010: 163).

My account of parenthood differs from existing role-based accounts primarily in its backward-looking viewpoint and its focus on filial obligations. Existing theories attempt to determine how to assign parenthood when a child is very young, perhaps even before he or she is born. For example, Brake's theory assigns parenthood based on who voluntarily accepts the social role of parents. ${ }^{9}$ Voluntary acceptance of the parental role is a commitment to perform certain future actions determined by social and legal expectations. Voluntary acceptance of this role usually occurs when the child is very young or before he or she is born. My account attempts to determine how to assign parenthood when the child is an adult. It attempts to determine who might be owed filial obligations. It bases parenthood on what people actually did for a child, rather than on their commitment to do something in the future.

I think my theory of parenthood as a role can help make sense of filial obligations in alternative family structures. This is valuable because many existing theories of filial obligations implicitly assume a biological account of parenthood. If we fail to challenge this assumption, then these theories will be unable to make sense of filial obligations in alternative family structures.

\section{Adoption}

Adoptive families are probably the most common form of alternative family. At its most basic, adoption involves two people taking responsibility for a child whom they did not conceive and birthe. However, adoption is a very broad category that can contain several of the other alternative family structures I will discuss in later sections. For example, a stepparent may adopt his or her partner's biological child, in which case one parent is biologically related to the child, while one is not. Or, grandparents may adopt their grandchild if the biological parents are unable to care for the child. In this case the parent is biologically related to the child, even though he or she is not the child's biological parent.

Assigning filial obligations in adoptive families is usually straightforward. If two adoptive parents fulfil the role of parents, then they will be the child's parents for the purposes of filial obligations. The most common difficulty that adoption causes for assigning filial obligations is determining what to do about biological parents who give their children up for adoption. If we are not clear about who counts as a parent for the purposes of filial obligations, then it can be difficult to determine if children have filial obligations to their biological parents, their adoptive parents, or both, in cases of adoption.

Do adopted children have filial obligations to their biological parents merely by virtue of the biological connection they share, even though their biological parents played no role in their upbringing? I think not, for the same reason I believe that the 
biological father from my example in the previous section is not owed anything by his child. Biological parents who give their children up for adoption have not fulfilled the role of parents, so my account of parenthood tells us that they are not parents for the purposes of filial obligations. They were not the individuals who took care of the child's needs, nurtured and cared for him or her, and showed a long-term interest in his or her development. It is the adoptive parents who have done these things for the child, so they are the child's parents and the people who are owed filial obligations.

There are, of course, more complicated cases that involve adoption. For example, a child's biological parents could remain involved in the child's life even after he or she has been adopted. In this case, the child could potentially have four parents. For this to happen, the child's biological parents would have to remain very involved in the child's life. They would have to take care of the child's needs, nurture and care for him or her, and show a long-term interest in his or her development into adulthood. This kind of continued involvement is not impossible, but it is not common, either.

\section{Surrogacy and IVF}

As medical technologies continue to advance and become cheaper, more people have access to IVF and the potential it brings for surrogate parents. In its simplest form, IVF involves fertilizing a woman's egg with a man's sperm outside the woman's body, then transferring the resulting embryo back into the woman's womb for gestation (Wald 2006-2007: 382-383). In these cases, the resulting child has two biological parents.

I am interested in more complicated cases of IVF involving a third person. For example, a lesbian couple may receive sperm from a close friend and undergo IVF to become pregnant. In this case, the child has a genetic father, a genetic mother, and a non-genetic mother. Or, for example, a woman may want a genetically related child, but be unable or unwilling to gestate a child herself. In this case, a gestational surrogate can be used. The woman's egg is fertilized with her partner's sperm, and then implanted into the surrogate. The surrogate then gestates and gives birth to the child. In this case, the resulting child has a genetic father, a genetic mother, and a gestational mother. The involvement of a third potential parent complicates both cases.

If we use the traditional biological account of parenthood, only two people will be parents in each case. This is problematic because it excludes some people who may want to be parents and includes some people who may have no interest in being parents.

In the case of the lesbian couple, we can assume that the non-genetic mother wants to be a parent. A purely biological account of parenthood excludes her, regardless of whether the genetic father remains involved with the child. It also includes the genetic father even if he does not want to be involved with the child.

There are two possibilities in the lesbian couple case, and the biological account of parenthood has trouble explaining both of them. First, we can suppose that both the genetic father and the child's mothers agree beforehand that only the mothers will be parents. In this case, we want a theory of parenthood that can account for only the mothers being parents. The biological account of parenthood cannot do 
this because it assigns parenthood to the genetic mother and the genetic father. Second, we can suppose that both the genetic father and the child's mothers want the genetic father to be a parent in addition to the mothers. In this case, we want a theory of parenthood that can account for three parents. Again, the biological account of parenthood fails to provide a satisfactory account. It limits the child to two parents, the genetic mother and the genetic father.

The biological account of parenthood fares slightly better in the gestational surrogate case. Again, at least two possibilities exist in this case. ${ }^{10}$ First, it is possible that the gestational surrogate is not interested in being a parent. In this case, she would no longer be involved in the child's life shortly after birth. We want a theory of parenthood that can account for only the genetic mother and the genetic father being parents. This is one of the few cases involving alternative family structures in which the biological account of parenthood can provide a satisfactory account. It tells us that the genetic mother and the genetic father will be the child's parents. The second possibility is that the gestational surrogate and the genetic parents want her to be a parent. The biological account will still determine that the genetic mother and the genetic father are the child's parents. This is problematic because it seems wrong to exclude the gestational surrogate if everyone involved wants to include her as a parent. We want a theory of parenthood that can account for the gestational surrogate as a parent when everyone involved in the child's life wants her to be a parent.

As we've seen, the biological account of parenthood fails to adequately handle most of these cases. I believe my account of parenthood as a role handles the cases much better. In the lesbian couple case, if the genetic father is not involved in the child's upbringing and does not fill the role of a parent, then only the genetic mother and the non-genetic mother will be parents. My theory of parenthood explains why only the mothers are parents. If the genetic father is involved in the child's upbringing and fills the role of a parent, then he is a parent along with the two mothers. My theory of parenthood as a role can account for the child having three parents.

My theory can account for each of the possibilities in the gestational surrogate case as well. If the gestational surrogate does not want to be a parent and does not fill the role of a parent, then the child will only have two parents. The genetic mother and genetic father will be parents because they fill the role of parents. If the gestational surrogate remains involved in raising the child, then she too can be a parent. Imagine a scenario where the surrogate sees the child every day and regularly takes care of the child in her home. She is also involved in important decisions about the education and health of the child. When the child is older, the gestational surrogate continues to play an active role in the child's life. This situation might occur if, for example, the gestational surrogate is the sister, or other close relative, of the genetic mother. In this case, the gestational surrogate fulfils the role of a parent, so she should be considered a parent for the purposes of filial obligations.

Depending on the gestational surrogate's level of involvement with the child, she may be owed weaker filial obligations than the child's other two parents; however, this would have to be determined by applying a theory of filial obligations to this case. My point is simply that, in this case, the surrogate should be considered a 
parent for the purposes of filial obligations. That is, she should be eligible for filial obligations.

Before moving on, I would like to point out that cases involving IVF and surrogacy, where more than two potential parents are in the picture, are not merely hypothetical. Several legal cases in the United States and Canada have grappled with situations like I've described. ${ }^{11}$ These cases almost always revolve around the custody of children born into situations where more than two people claim to be parents. Again, I am not interested here in the legal question of who counts as a parent, but these cases demonstrate that the question of who counts as a parent is not only a philosophical question.

\section{Extended family}

I think one can identify at least three cases in which extended family can be parents. The first case involves parents who separate or divorce while their children are young. If one or both parents become involved in a long-term relationship with another partner, then these new partners become the children's stepparents. The second case involves multi-generational households, in which a child's parents and grandparents live in the same house. The third case involves households with several members of the same generation living together. Here I have in mind cases where children live with their parents and their parents' siblings. I argue that the traditional biological account is not able to make sense of these relationships, while my account of parenthood as a role does.

In the case of stepparents, I think it is important that children establish a relationship with their stepparents while they are still young. Recall that to be considered a parent for the purposes of filial obligations, someone must take care of a child's needs, nurture and care for him or her, and show a long-term interest in his or her development into adulthood. I do not know if it is possible to specify a precise age at which a child can no longer form the required relationship with a stepparent. Much would depend on the individual child's development and openness to a new parental relationship. I speculate that it would be relatively easy for a dedicated stepparent to form the required relationship with most children under five, but it would get more difficult as the child continues to age. Past a certain age, showing a long-term interest in a child's development would become difficult because the child is already developed. Similarly, it would be difficult to nurture and care for a child if the child is mostly self-reliant. It would be very difficult for a stepparent to do these things with a child who is 20 years old, for example.

The traditional biological account tells us that only the children's biological parents should be parents. My account of parenthood as a role explains how stepparents can be parents. So long as they fill the role of parents, they are parents for the purposes of filial obligations.

When we include stepparents as potential parents, it is possible for a child to have at least four parents, if both parents remarry or become involved in long-term relationships. ${ }^{12}$

In the case of multi-generational households, I have in mind children who grow up living with both their biological parents and one set of their grandparents. This may occur if a couple has a child when they are quite young and are unable to care 
for the child on their own. Or, it may occur in cases where it is not economically viable for the child's parents to live elsewhere. The traditional biological account of parenthood would only acknowledge the biological parents. My account of parenthood as a role tells us that as long as the grandparents take care of their grandchild's needs, nurture and care for him or her, and show a long-term interest in his or her development, they will be parents for the purposes of filial obligations. In cases like this, a child could have two biological parents and two grandparents who fill the role of parents, for a total of four parents.

In the case of households with several members of the same generation living together, I have in mind children who grow up with their biological parents and their parents' siblings. This could occur if siblings live together as roommates and one of them has a child. In these cases, children could have three or more parents, depending on the number of their biological parents' siblings involved.

The American sitcom Full House provides a good fictional example of a household with members of the same generation living together. In the show, Danny Tanner is faced with raising his three daughters, Michelle, Stephanie, and D.J., alone after their mother dies in a car accident. To help Danny, both his best friend Joey and his brother-in-law Jesse move into Danny's house. Together, they raise the three girls. In later seasons of the show, Jesse's wife Becky moves into the house and cares for the children as well. Michelle, Stephanie, and D.J. all develop strong relationships with the four adults in the house. Over the course of the show's eight seasons, all four adults take care of the children's needs, nurture and care for them, and show a long-term interest in their development into adulthood. They refer to each other as a family and the children even call Joey 'Uncle Joey'.

The biological account of parenthood would only acknowledge Danny as a parent. My account of parenthood as a role acknowledges that Michelle, Stephanie, and D.J. have four parents for the purposes of filial obligations. Danny, Joey, Jesse, and Becky all play an important role in raising the children. Though only Danny is biologically related to the children, all four adults in their lives fill the role of parents.

\section{How many is too many?}

While I think my account of parenthood better explains alternative family structures than does the traditional biological account, it is also open to a potentially serious objection. We might worry that extending parenthood to more than two people would make it impossible to restrict parenthood to a reasonable number of people. If a child can have three or four parents, why not ten or twenty? We may think that anyone who cares for a child can be a parent. If that is true, and a child has many frequent caregivers, then the child could have many parents. For example, a particularly involved family friend, a teacher, or a caretaker, might all meet the conditions of my account of parenthood. Combined with two biological parents and two stepparents, children could easily have seven parents or more. This is a concern because we typically think of parent-child relationships as very intimate, and it is difficult to have intimate relationships with a large group of people. If a child has too many parents, they might lose out on the intimacy that makes parent-child relationships special. If my account of parenthood leads to cases like this, then it 
may be too inclusive, that is, it may include people as parents who should not be parents.

The problem of having too many parents is of particular concern for filial obligations. Filial obligations are sometimes perceived as too burdensome even when a child has only two parents (Welch 2012: 725-729). The severity of this concern varies with the content of filial obligations. If children have strong filial obligations, for example, to provide any and all care their parents need, then their obligations could be very burdensome should their parents become ill. However, if children only have weak filial obligations, for example, to keep in touch with their parents, then it is unlikely that their obligations would become very burdensome. Regardless of the content of filial obligations, adding more parents would increase the amount of work children must do to discharge those obligations. However, this only becomes a weighty concern if children have strong filial obligations. If having strong filial obligations to two parents is potentially overly burdensome, then having six, eight, or ten parents would almost certainly be overly burdensome. Children could be required to spend a great deal of time, energy, and money to meet their obligations.

Fortunately, I think the definition of parenthood I am using will eliminate most extreme examples of children with too many parents. I believe that taking care of their children's needs, nurturing and caring for them, and showing a long-term interest in their development into adulthood places a practical limit on how many people could count as parents. For example, most teachers, close family friends, and caretakers will not meet the definition of parenthood because they fail to do one or more of these three things for children. Though they all care for children, they rarely provide the degree of care required to be a parent.

Teachers are rarely able to show a long-term interest in a child's development. Their direct involvement in a child's life is usually limited to a year or two. Even if a child has the same teacher throughout elementary school, their contact is likely to diminish greatly once the child leaves the school. Generally, once a child leaves their class, teachers do not remain involved in the child's life.

Close family friends may nurture and care for a child and may even show a longterm interest in the child's development, but they are unlikely to be the people responsible for taking care of the child's needs. Usually the individuals who are responsible for taking care of a child's needs will live with the child so that they can consistently provide what the child needs. Close family friends do not usually live with the family. There may be unusual cases, like Joey in Full House, but most close family friends will not meet the three conditions for parenthood.

Caretakers are unlikely to be parents unless they are very involved in the process of raising a child. Babysitters, for example, are not parents because they do not take a long-term interest in a child's development. Babysitters take care of a child for a short time when the child's primary caregivers are unavailable. They are not sufficiently involved with the child's life to demonstrate a long-term interest in his or her development. On the other hand, a sufficiently involved caretaker could be a parent. For example, suppose a caretaker is employed to provide full-time care for a child. The caretaker is the child's primary caregiver during the day, is responsible for meeting the child's needs, and cares for the child throughout most of the child's developing years. In this case, the caregiver seems to meet all three conditions for 
parenthood, and so should be considered a parent for the purposes of filial obligations.

Using my definition of parenthood rules out many people who provide some care for children, and minimizes extreme cases, like a child having ten parents for the purposes of filial obligations. Someone must be dedicated to raising a child in order to meet my three conditions for parenthood. That said, I do not believe it is possible to set a strict upper limit on the number of parents a child can have, since too many unusual cases could occur. For example, we can imagine a case where a child has biological parents, stepparents, grandparents, a close family friend, and a caregiver who all count as parents using my definition of parenthood. It would be a very unusual case to be certain, but it could happen.

Outside of imagined cases, I think it will be rare to find cases where children have even three or four people who demonstrate enough care for them to count as a parent using my account of parenthood. Even focusing solely on the alternative family structures I have discussed, children usually do not have more than three or four parents. Adoptions typically involve the biological parents giving up contact with their child, or at least the kind of contact required to meet my conditions for parenthood. IVF and surrogacy usually involve at most three or four people, so, by themselves, they are unlikely to lead to situations where a child has more than three or four parents. Cases involving extended family seem to have the greatest potential to lead to situations where children have more than four parents.

Even in extended family cases, it would be extremely unusual for a child to have more than four people who count as parents using my account of parenthood. Being a parent is hard work and involves a lot of sacrifice. Most children aren't lucky enough to have more than a few people willing to make sufficient sacrifices for their wellbeing. However, in the unusual cases where more than three or four people have taken care of a child's needs, nurtured and cared for him or her, and shown a longterm interest in his or her development into adulthood, they should all be considered parents.

Given that these situations are extremely rare, I do not believe they will be a real concern for my theory. Some children may end up with more burdensome obligations than if using a traditional biological account of parenthood, but very few will end up with a significantly greater burden. Most children will still have two parents, a few will have three or four, and a tiny fraction will have more than four. I think the explanatory power of my theory of parenthood for people in alternative families more than outweighs the rare cases where a child might be assigned overly strong obligations.

\section{Too many cooks in the kitchen}

In addition to the worry about creating overly burdensome obligations, another potential concern is that having too many parents will make it difficult to settle disagreements. It can be difficult for two people to agree on important decisions for their child, so adding more opinions may make agreement even more difficult. Melanie Jacobs calls this the "too many cooks in the kitchen" problem (Jacobs 2007: 326). Jacobs approaches this problem from a legal perspective, and so is primarily concerned with custody and visitation rights. However, I think this problem could arise in non-legal contexts as well. Even seemingly simple decisions, such as what to 
have for dinner or who will cook it, become trickier when more people are involved. Important decisions have the potential to be even more difficult. Deciding where to send a child to school, or whether to take a child to the hospital after a minor bike accident, for example, could be considerably more challenging for four parents than for two.

Jacobs argues that while we are rethinking parentage we must also consider the relative rights of each parent involved. She suggests that a parent who is the primary caregiver for a child should have greater rights when making decisions about raising the child than a parent who contributes less financial and emotional support (Jacobs 2007: 326). For example, other things being equal, if one parent regularly takes their child to the park or on other outings while the child's other parents do not, that parent should have greater decision making power. Jacobs's justification for giving greater rights to the primary caregiver is that the primary caregiver has a closer relationship with the child. Presumably, the parent with the closest relationship to the child will have the best understanding of the child's needs.

Jacobs also claims that even if having more parents leads to more disagreements, it will also lead to greater security of care for a child. Having more parents involved with raising a child means that more people are deeply invested in the child's development and wellbeing. For example, if a child with four parents is ill, more people are available to stay home from work and care for the child than if the child had only two parents. Jacobs argues that greater security of care for the child helps to mitigate any harm that comes from an increase in disagreements among parents.

\section{Gendered distribution of labor}

The final concern I would like to address is related to the distribution of work between parents. We might worry that increasing the number of parents involved in raising a child could lead to an imbalanced distribution of labor. If a child has four parents, one or two parents might get away with doing less work while still enjoying all the benefits of being a parent. Since four people are now responsible for the same care that is usually provided by one or two, it might be easier for one of them to do less than they should.

In particular, we might worry that this unfair division will be gendered, that is, women will end up doing more work than men. In traditional two-parent families, women tend to spend significantly more time providing childcare and performing household labor than do men. For example, in Canada in 2010 women spent an average of 50.1 hours per week on unpaid childcare while men spent an average of only 24.4 hours per week (Statistics Canada, 2015). This means that women spent an average of 25.7 hours per week more than men did on childcare. Similarly, women in Canada in 2010 spent an average of 13.8 hours per week on unpaid household labor while men spent an average of only 8.3 hours per week (Statistics Canada, 2015). This means that women spent an average of 5.5 hours per week more than men did on household labor.

In families with more than two parents, the concern could arise that the gendered division of household and childcare labor might be more pronounced than in traditional two parent families. For example, in a family with two biological parents and two grandparents who fill the role of parents, the mother and grandmother might do an even greater share of the work. Simply having more 
women available to provide childcare and perform household labor could increase their share of the unpaid work. Each woman might do less than she would in a traditional two-parent family, but combined they might do a greater total share of the work. If this happens, the father and grandfather would end up doing an even lesser share of the work than they would in traditional two-parent families.

The possibility that allowing for more than two parents in a family might lead to a more imbalanced and gendered distribution of labor is a serious concern. However, I don't think the problem is an inherent result of expanding our conception of parenthood. It is possible to have a family with two mothers and two fathers who split caring labor roughly equally. If an imbalanced and gendered division of labor results from an expanded conception of parenthood in practice, then it certainly warrants correcting the issue. However, I do not think it is a reason to give up on expanding the conception of parenthood.

While an imbalanced distribution of labor is problematic for fairness reasons, it also has implications for filial obligations. For the purposes of filial obligations, an imbalanced distribution of household and childcare labor might lead to children having stronger filial obligations to some of their parents than to others. Much as Jacobs thinks that parents who provide more emotional and financial support to their children should have greater rights when making decisions about their children, it seems reasonable that children should have stronger filial obligations to the parents who spent more time caring for them. For example, if a child has two mothers and two fathers, but the mothers do the majority of labor involved with raising the child, it seems reasonable that the child will have stronger filial obligations to his or her mothers than to his or her fathers. How much stronger the child's obligations to his or her mothers would be will depend on which theory of filial obligations we use, which is beyond the scope of this paper.

If children have stronger filial obligations to the parents who spent more time caring for them, it might help mitigate some of the concerns about an imbalanced and gendered distribution of caring labor. While mothers might end up doing more childcare and household labor than fathers, they would also be owed stronger obligations by their children. If children have stronger obligations to their mothers, the mothers might receive better care from their children than do the fathers. In some sense, the mothers would be rewarded later in life for the work they did when their children were young. However, even if this were the case in practice, it does not solve the fairness concern. It would still be better if the distribution of care and household work between mothers and fathers were more equal.

\section{Conclusion}

I began this paper by seeking to determine who counts as a parent for the purposes of filial obligations. To show why this is important, I demonstrated that a traditional account of the family can create problems for existing theories of filial obligations. In particular, the special goods theory of filial obligations has difficulty distinguishing parents from other close family members. I then argued that we can solve this difficulty by expanding our conception of parenthood beyond a traditional biological account to a role-based account. From this perspective, we define a child's parents as the individuals who take care of the child's needs, nurture and care for him or her, and show a long-term interest in his or her development 
into adulthood. If we move from a traditional biological account of parenthood to an account of parenthood as a role, we see how other close family members can be parents. This explains why the special goods theory of filial obligations has trouble distinguishing between parents and close family members in some cases. These close family members are really additional parents, so there is no meaningful distinction to make.

I then examined three cases of alternative family structures: adoption, surrogacy, and extended family. I argued that understanding parenthood as a role allows us to make better sense of these cases than can a traditional biological account of parenthood. Understanding parenthood as a role allows us to account for people who should be parents in these cases, but whom the traditional biological account would exclude. It also allows us to exclude people who shouldn not be parents that the traditional biological account would include as parents. This explains how children can have filial obligations to more than two people, and to people who are not their biological parents.

In the final section, I addressed three related concerns about having too many parents. First, I addressed the concern that having too many parents might make filial obligations overly burdensome. Second, I discussed Melanie Jacobs's concern that having too many parents in a family will make decision making difficult. Finally, I considered the possibility that allowing for more than two parents could worsen the imbalanced and gendered distribution of childcare and household labor.

\section{Notes}

${ }^{1}$ Since these assumptions are implicit it is somewhat difficult to cite specific examples. No one, as far as I know, explicitly states that only biological parents are parents. However, most authors use the term 'parents' without any analysis of whom that includes. I take this to mean that these authors are using the traditional account of the family or something not very far off. For example, Jane English's friendship theory of filial obligations (English, 1999), Christina Hoff Sommers's work on filial obligations (Hoff Sommers, 1986), and Brynn Welch's gratitude for special goods theory of filial obligations (Welch, 2012) do not discuss the nature of parenthood at all. Simon Keller (Keller, 2006) and Claudia Mills (Mills, 2003) mention adoption, but not adoption by same-sex couples, surrogacy, or extended family.

${ }^{2}$ There is a small body of work in philosophy more generally on families with more than two parents. See (Brennan and Cameron 2015) for more.

${ }^{3}$ Some provinces in Canada have filial obligation laws. See (Bracci, 2000).

${ }^{4}$ Certainly Welch's theory (Welch, 2012) and English's theory (English, 1999) are compatible with alternative family structures. Keller seems to give preference to biological parents (Keller 2006: 265-266), but his special goods theory is compatible with alternative family structures.

${ }^{5}$ See (Keller, 2006) and (Mills, 2003).

${ }^{6}$ See (Brake \& Millum, 2016) and (Austin, 2007).

7 It is children's interests that do the normative work in my definition of parenthood. That said, since my theory is backward-looking, I am only concerned with who actually met a child's interests. I'm not concerned with who could have been the best possible parents to a child. This allows my theory to avoid concerns 
about redistributing children to the best possible parents or being unable to determine who would best promote a child's interests (Austin 2007: 30-32).

${ }^{8}$ I call my account a role-based account because a child's parents can be anyone who satisfies the child's interests. I have in mind something akin to what Elizabeth Brake calls 'social parents'. She says, "Biological parenthood is often contrasted with social parenthood, where the social parent actually rears the child (Brake 2010: 152)." My account stipulates the conditions someone must have satisfied to fill the role of a social parent for the purposes of filial obligations.

9 Though, I take it that, according to Brake's theory, someone could voluntarily accept the role of parenthood and become a parent to a young child, but then lose their status by failing to manage properly their rights and responsibilities to the child.

${ }^{10} \mathrm{I}$ am ignoring the possibility that the gestational surrogate could want to be a parent while the genetic parents do not want her to be a parent. This is, of course, a possibility, but it will only occur if something changes during the gestation period. Ideally, everyone involved in a surrogacy relationship agrees beforehand who will be the child's parents.

${ }^{11}$ See (Johnson v. Calvert, 1993), (In re Marriage of Moschetta, 1994), and (J.F. v. D.B., 2004) for examples.

${ }^{12}$ A child could have more than four parents if he or she has more than two parents before stepparents are introduced.

\section{References}

Austin, Michael W. (2007). Conceptions of Parenthood: Ethics and the Family. Hampshire: Ashgate Publishing.

Bracci, Christa. (2000). "Ties That Bind: Ontario's Filial Responsibility Law." Canadian Journal of Family Law 455-500.

Brake, Elizabeth. (2010). "Willing Parents: A Voluntarist Account of Parental Role Obligations." In Procreation and Parenthood: The Ethics of Bearing and Rearing Children, by David Archard and David Benatar, 151-177. Oxford: Oxford University Press. https://doi.org/10.1093/acprof:oso/9780199590704. 003.0007

Brake, Elizabeth, and Joseph Millum. (2016). "Parenthood and Procreation." The Stanford Encyclopedia of Philosophy. https://plato.stanford.edu/archives/ win2016/entries/parenthood

Brennan, Samantha, and Bill Cameron. (2015). "How Many Parents Can a Child Have? Philosophical Reflections on the 'Three Parent Case'." Dialogue (54): 4561. https://doi.org/10.1017/S0012217314000705

English, Jane. (1999). "What Do Grown Children Owe Their Parents?" In Morals, Marriage, and Parenthood: an Introduction to Family Ethics, by Laurence D. Houlgate, 267-271. Belmont, CA: Wadsworth.

Hoff Sommers, Christina. (1986). "Filial Morality." The Journal of Philosophy 83 (8): 439-456. https://doi.org/10.2307/2026329

In re Marriage of Moschetta. (1994). 30 Cal. Rptr. 2d 893 (Cal. Ct. App.).

J.F. v. D.B. (2004). 66 Pa. D. \& C.4th 1, 3 (C.P. Ct. Erie County) 
Jacobs, Melanie B. (2007). "Why Just Two? Disaggregating Traditional Parental Rights and Responsibilities to Recognize Multiple Parents." Journal of Law \& Family Studies 309-339.

Johnson v. Calvert. (1993). 851 P.2d. 776 (California Supreme Court).

Keller, Simon. (2006). "Four Theories of Filial Duty." Philosophical Quarterly 56 (223): 254-274. https://doi.org/10.1111/j.1467-9213.2006.00441.x

Mills, Claudia. (2003). "Duties to Aging Parents." In Care of the Aged, by James M. Humber and Robert F. Almeder, 145-166. Humana Press. https://doi.org/ 10.1007/978-1-59259-349-1_7

Statistics Canada. (2015). "Time spent on household domestic work, by working arrangement, Canada, 2010." Statistics Canada. 11 30. Accessed 11 13, 2016. http://www.statcan.gc.ca/pub/89-503-x/2010001/article/11546/tbl/tbl007eng.htm.

(2015). "Time spent on unpaid care of a child in the household, by working arrangement and age of youngest child, Canada, 2010." Statistics Canada. 11 30. Accessed 11 13, 2016. http://www.statcan.gc.ca/pub/89-503$\mathrm{x} / 2010001 /$ article/11546/tbl/tbl006-eng.htm.

Wald, Deborah H. (2006-2007). "The Parentage Puzzle: The Interplay Between Genetics, Procreative Intent, and Parental Conduct in Determining Legal Parentage." Journal of Gender, Social Policy \& the Law 379.

Welch, Brynn F. (2012). "A Theory of Filial Obligations." Social Theory and Practice 38 (4): 717-737. https://doi.org/10.5840/soctheorpract201238438

Young, Alison Harvison. (1997-1998). "Reconceiving the Family: Challenging the Paradigm of the Exclusive Family." Journal of Gender \& The Law 505-555. 